\title{
Two educators reflect on their immigration experience through creative writing
}

\author{
Reflection report \\ Jasna K. Schwind ${ }^{1}$, Oi Ling Helen Kwok ${ }^{2}$ \\ ${ }^{1}$ Daphne Cockwell School of Nursing, Ryerson University, Ryerson University, Toronto, Ontario, Canada; ${ }^{2}$ School of \\ Arts and Science, Seneca College, Toronto, Ontario, Canada
}

Corresponding author: J. K. Schwind (jschwind@ryerson.ca)

\begin{abstract}
Following Dewey's philosophy of experience that all our life events inform how we evolve, both personally and professionally, two educators reflect on their immigration experiences. Being uprooted from one's place of birth to another, at an oftentimes turbulent stage of development, young people face challenges in finding their sense of belonging. We engage in creative writing to reflect on our respective experiences of immigration to Canada to support our scholarship of teaching and learning. Using Dewey's three criteria of experience: continuity, relationship, and situation, and Connelly and Clandinin's Narrative inquiry self-study framework, we delve deeper into understanding how the transplantation from one continent to another continues to affect who we are today as persons and professionals. This critical reflection is of further value to us as educators in gaining a greater appreciation for our students' experiences, many of whom live their own stories of immigration. In doing so, we hope to more effectively support and encourage students, not only to survive, but to thrive in their new landscape. We trust our work will be, likewise, of service to educators worldwide who want to engage in their own inquiry of personally significant life events, and thus support the same in their students.
\end{abstract}

\section{KEYWORDS}

Creative Writing, Education, Experience, Immigration, Reflection

\section{BACKGROUND}

Life's nodal events have equal potential for great learning, growth, and connection, as well as for pain, loneliness, and longing. We often call these life turns, transitions. This term may denote different meanings for the reader, depending on the context and the lens through which it is examined. For our purposes, we define transition as moving from one landscape to another, as if transplanting a young tree from one garden to another. The young tree is uprooted and moved, with the hope it will continue to grow, and even thrive, in the new garden landscape. In this article we explore one such life transition: migration between countries and continents. In a similar vein, we use the term migration interchangeably with immigration and emigration to denote our personal experiences of transplantation from our respective birth countries to Canada.

\section{PURPOSE \& STRATEGY}

We met at the university in 2015 . Helen, a graduate student in Early Childhood Studies, was seeking a supervisor for her master's thesis using narrative research. Jasna, a senior professor and narrative researcher in the School of Nursing, answered the call. Today, as colleagues, we explore our shared immigrant experiences through critical reflection and creative writing.

In this article, using the narrative inquiry self-study framework (Connelly \& Clandinin, 1990, 2006), which 
is informed by John Dewey's (1963/1938) three criteria of experience: continuity, relationship, and situation, we reflect on this significant life transition. In line with Dewey's philosophical perspective on experience and education, we believe that "without some reconstruction, some remaking" of our life experiences there is no intellectual evolution (Dewey, 1963 , p. 64). Consequently, this reflective process serves to help us make sense of our respective lived immigrant experiences, while considering how this major personal event that took place in our early teenage years, continues to shape our personal and professional lives as educators, today.

\section{MAIN POINTS}

\section{Philosophical Perspectives}

Experience moves from being lived (ontology) to being articulated for the purposes of understanding and knowledge development (epistemology), and finally, based on critical reflection and intellectual deliberation, to being enacted in practice (praxis).

In his important book, Experience and Education (1938/1963), Dewey articulates his philosophy of experience, wherein he identifies three criteria of experience: continuity, relationship and situation. In other words, experience happens over time, in relationship, and in a particular location or a series of locations. This philosophical stance underpins the narrative inquiry research approach (Connelly \& Clandinin, 1990), which guides our respective scholarship of education, discovery, and praxis.

More specifically, in terms of continuity, Dewey observed that "every experience enacted and undergone modifies the one who acts and undergoes, while this modification affects, whether we wish it or not, the quality of subsequent experiences" (1963, p. 35). This notion denotes experience as continuously unfolding and evolving. When intentionally reflected upon in the present moment, past experiences have the potential to positively inform one's future ways of being, knowing, and doing. Dewey identified these experiences as educative, a significant consideration when crafting teaching-learning encounters.

Experiences happen in relationship to self and to other. Dewey noted that "all human experience is ultimately social: that it involves contact and communication" (1963, p. 38). In narrative inquiry we recognize the value of our inner world and how that quality deepens our relationships and our understanding of the external environment. Thus, the narrative inquiry self-study framework allows us to examine our own experiences in order to understand how they influence our relationships with others, including our students.

As such, the personal-social interaction within a given context, creates the third criterion of experience, situation. Notably, experience unfolds in a situation or a series of situations, often referred to as places (Clandinin \& Connelly, 2000). When thought of in the context of migration, the individual experiences unfold over time, in relationship across diverse social contexts and physical landscapes. Dewey wrote that "experience is always what it is because of a transition taking place between an individual and what, at the time, constitutes [their] environment" (1963, p. 43).

Stories of our life experiences, when reflected upon and shared with others, contribute to the development of humanistic relationships. Thus, narrative inquiry facilitates teachers and students to tell their stories of experience, not only for their own learning, but that of others (Schwind, 2008). Clandinin and Connelly (2000) believe that narratives should embrace an invitational component, encouraging readers to reflect on their own experience and practices, which promote potential positive changes in their lives.

\section{Narrative Inquiry Self-Study}

According to Connelly and Clandinin (1990), whose development of narrative inquiry qualitative research approach is heavily informed by Dewey's philosophy of experience, the closest we come to experience is through telling stories of that experience, thus creating the possibility for learning. Using the narrative inquiry framework, the experiences are deconstructed into their component parts, critically reflected upon using scholarly literature, and then reconstructed with new meaning in place (Clandinin \& Connelly, 2000). In other words, through that expanded understanding we create the potential to "transform our lives, and consequently the lives of those" in our educational care (Schwind et al., 2012, p. 3). This perspective is supported by the recognition that our personal and professional lives are intimately 
entwined and thus mutually informing (Connelly \& Clandinin, 1988; Dewey, 1963/1938; Lindsay, 2008).

Reflective process is the keystone of self-study, a prominent approach for narrative inquiry (Shields et al., 2011), especially when it allows inquirers to write about events and situations that connect their past and present, revealing the many layers of their own experiences. Bullough and Pinnegar (2001) note that self-study has the capacity to provide insight and guidance, helping readers learn from others' experiences. They claim that "ultimately, the aim of self-study research is moral, to gain understanding necessary to make interaction increasingly educative," not only enriching one's own practice but that of others (p. 15). As such, educators are encouraged to turn inward and embark on a journey to connect and share their life stories, so that they and their students may be enriched (Aksenchuk, 2020; Shields et al., 2011).

Like Dewey, and Connelly and Clandinin, Dinkelman (2003) recognizes the value of reflective practice for educators. He writes that "self-study is not the whole of teaching, but it mirrors and systematizes that part of pedagogy that is reflection" (p. 9). This suggests that self-study can be a formalized form of reflection that is thoughtful and educative (Di Stasi, 2020). In Dewey's (1916) words, it is a "reconstruction or reorganization of experience which adds to the meaning of experience, and which increases ability to direct subsequent experience" ( $p$. 76). Clandinin and Connelly (2004) agree that selfstudy "holds the highest possible potential for improving education" (p. 597).

Therefore, to be more effective educators, it behooves us to engage in self-study. Through such self-reflective process we explore our own lived experiences, and thereby gain a deeper understanding of how our personal life events affect our professional relationships with students. Thus, self-study can inform our practice and offer "insight and solution for public issues" (Bullough \& Pinnegar, 2001, p. 15), with the view that we teach ourselves, so through that process others may learn (Pinar, 1981).

With the purpose of extracting a deeper meaning of the storied events, using narrative inquiry selfstudy, we enter into reflective dialogue with ourselves, with each other, and with the extant literature (Schwind et al., 2012). This intra- interpersonal engagement invites individuals to discover their way of being and to reconstruct their experiences through storytelling, as well as to coconstruct knowledge in relationship with each other. It is important, however, to maintain flexibility and openness to the ever-changing inner and outer landscapes, as we reconfigure our understanding of our life events. According to Clandinin and Connelly (2000), the inner landscape expresses our thoughts, feelings and hopes, and the outer landscape denotes social conditions and the physical environment. These landscapes are mutually informing and in dynamic engagement with the relational and temporal dimensions of experience.

Clandinin and Connelly (2004) contend that a thoughtful self-study is a rich source of knowledge, because of the "experiential base of the self-knower, which has the potential to reveal the educational and professional landscape" (Di Stasi, 2020, p. 26). Thus, understanding who we are as persons and educators through our lived experiences, we have the potential to disrupt the taken for granted perspectives (Clandinin \& Connelly, 2000). Bullough and Pinnegar (2001) suggest that when we examine our stories of experience through self-study, it is no longer an individual endeavor, rather it becomes a coconstruction of knowledge that is socially significant that others can learn from.

Through reflection, individuals feel located and connected to their circumstance, which in turn cultivates increasing confidence in coping with changes that often feel like being betwixt and between. This liminal space of increased potentiality, where one is in transition between the previous way of being and the possibilities that are yet to be revealed, aligns with Dewey's (1929) notion of uncertainty. Although the term disruption may have a negative connotation, all disruptions are opportunities for intentional reflection and learning on "how to live in the world" as a result of that experience (Lindsay et al, 2016, p. 7). If this narrative inquiry self-study is working, readers will feel invited to engage in their own inquiry, considering significant life events in their own lives and how these inform their educational relationships.

\section{Creative Writing}

We recognize that stories may be articulated through various modes of expression, such as storytelling, 
metaphors, creative writing, dance, visual art, and others (Schwind, 2008; 2016). Following Dewey's philosophy that experience is education, we reconstruct experience through creative writing to access tacit knowing (Polanyi, 1966/2009; Schwind, 2003; 2016; Schwind \& Lindsay, 2016). Eisner (2002) observed that "through the arts we learn to see what we had not noticed, to feel what we had not felt" ( $p$. 12). In other words, our reflection on the role of immigration in our personal and professional lives was enhanced through creative self-expression, making "tangible manifestation of [our] thinking" (Schwind \& Lindsay, 2016, p. 483). In this article we use creative writing, in the form of prose, as a way to access our lived experiences of immigration.

In this segment we share two pieces of writing. Although our respective immigration experiences took place during our teenage years, they happened decades apart and involved different continents. Our writings, similarly, came into being many years apart, before we came to engage in the graduate supervision relationship. As each of us independently engaged in creative reflective writing, it was the language transition of the selected two pieces that inspired us to further reflect and collaborate on this work.

Over the months of crafting this reflective piece, we read each other's writing and shared our experiences. We met numerous times to talk about our individual life and immigration experiences, exploring resonances and the notion of common humanity. Our meetings were interspersed with individual reflection and pondering, thus deepening the reflective process. Once the two key patterns emerged, we accessed research literature to deepen our understanding of how these patterns may inform, not only our, but immigrant experience as a whole. Following the perspective that who we are as persons is who we are as professionals (Connelly \& Clandinin, 1988), as educators, we were also curious how these two key patterns may inform our teaching-learning encounters.

The first piece of writing is Jasna's expression of her immigration experience using poetic prose. The first part of this writing is in her mother tongue, Croatian. As the writing progresses, the language changes from Croatian to English, denoting the movement and acclimatization from one landscape to another. In the second piece of writing, Helen denotes her immigration experience. In like manner, Helen writes aspects of her story in Cantonese, as she transitions to the landscape of the new country. Through our creative writing, we both express tensions as we transition from one place to another, and as we strive to survive and eventually thrive in our new landscape; what for us is a sense of belonging.

\section{Longing to Belong}

Prije tridest-pet godina dođosmo tu [Thirty-five years ago we arrived here]

Mutavi sa riječima ...Sami. [With muted words; alone]

Ošli u tuđi svit [We left for foreign land]

Graditi novo gnijezdo [To build a new nest] Teško ostaviti rodni kraj ...svoj govor, svoj narod. [It was difficult to leave our birthplace, our language, our kin.]

I polako, korak po korak, mama veli. [And slowly, step by step, mom says.]

We start to climb Tata kaže, I to će proć [Dad says, and that too shall pass]

But, it's hard work.

New language. New people. New challenges.

Korak po korak ... Pa nije tako loše.[Step by step ... Well, it's not so bad]

The old country all but faded Loved ones tired of waiting for our return, leave this world

while we're busy working, making a living...surviving

Our home is here now.

We let our roots grow into this new soil ... Al' stari kraj nam je još uvik u srcu ... i u duši [But the old homeland is still in our hearts ... and in our soul] We, the immigrants, the transplants, are of two worlds ... of many worlds

We seem to belong everywhere And yet, we belong nowhere ...

$\sim \|^{\sim}$

I ponder these thoughts as I think of my visit back this past June...

Ja nisam stranac tu na tom tlu. [I am not a stranger in this part of the world]

Svi me znaju. Svi me razume.[Everyone knows me, everyone understands me.] 
And yet, when I speak, they ask me where I am from ... because I have an accent...

Much time has elapsed since we left the old landscape,

I see it through new eyes

Life experiences have intervened ... I have changed ... They have changed ...

Life has moved on, like a river on its eternal journey to the sea... the same river, yet different...

$\sim|I| \sim$

We, the fifth-dimension people, are often

Reflective ...torn ...longing to collect strewn pieces of ourselves ... hoping to heal.

We seem to belong nowhere,

Yet, we belong everywhere.

J. K. Schwind, 2004

\section{Stepping Stones}

\section{Leaving home for the new country}

I am seventeen years old. With two pieces of luggage and a dictionary, I arrive at Toronto Pearson International Airport. Alone. Standing in front of an immigration officer, I am nervous and scared. At first, he is flipping through my passport and typing information into the computer. When he asks me the reason for my visit, my mind immediately answers, " 我唻加拿大係為尋找我好好嘅將夾” (I am here to search for a better future), but I hold back. I tell him I am here to study. "Welcome to Canada!" he says. This is how my life journey, as an immigrant, begins.

\section{Transition there to here}

My favourite routine is walking through the falling snow to catch the bus to school. I enjoy having countless light, fluffy snowflakes softly land on my face. Although they fall from great heights, they are gentle and sensitive, as if they recognize my struggles being an immigrant and try to comfort me. "Today you will sit in a group of four to discuss the topic I place on your table", says the professor. It is my turn to speak. While spending an extra minute to collect my thoughts, another classmate interrupts, "Why don't we come back to her, she doesn't speak English. Maybe she needs extra time to translate the topic." My inner voice screams silently, "No! I fully understand what it means. I just need extra time to put my thoughts together." At the end, I never have a chance to speak.

\section{Return home - Tug of war, where do I belong?}

I am finally returning to visit my 'home' in Hong Kong. I feel the warmth and love as my Mom and Dad tightly embrace me in their arms. “嘩！你好似 轉變好多哃! ”(You seem to have changed a lot!), they mumble. I tell them I am still the same person and daughter they knew before. I begin to share with them my life experiences in Canada. They nod but look perplexed. My Dad asks, “點解你啲中文表達能 力退步咗咁多嘅? 我好難去完全明白你呀! ”Why do you have a hard time expressing yourself in Cantonese? I am having trouble understanding you). His comment makes me feel puzzled and lost. In Canada, my voice is not fully heard. In Hong Kong, my family has a hard time understanding me. I'm confused. Where do I fit in?

Oi Ling Kwok (2017)

\section{Reflection}

As educators, we believe that beginning with ourselves (Hunt, 1987) serves to deepen our understanding of who we are as instruments of education (Schwind et al., 2012), in order to better support our students to thrive, as they encounter their own life histories. Using Dewey's three criteria of experience, we reflect on our stories and consider how our expanded understanding of our immigration experiences many years ago may inform our respective professional roles as educators today. We are cognizant that our creative writing may be examined from many different perspectives, and that numerous issues, challenges, and joys that immigrants encounter could be analyzed through various theoretical lenses. However, for the purposes of this writing, in alignment with narrative reflection informed by Dewey's philosophy and Clandinin and Connelly's (1998; 2000) narrative inquiry self-study, we elect to focus on two narrative patterns, which, after reading and re-reading our stories, emerged as significant to our own experiences: transition, as we travel backwards and forwards in time and across physical places; and a sense of belonging, as we acclimatize and shift from surviving to thriving in our new landscape.

\section{Transition}


Migration is a transition "from one country, region, or place of abode to settle in another" (Webster's, 1989, p. 908). In other words, it entails moving from one habitat to another, usually a distant one. Transition is described as a process individual undertakes in their various life situations, over time, and across places. We see both migration and transition as dynamic and challenging. Physically, this process may take a matter of hours, as is the case of taking an intercontinental flight. Emotionally, this transition may span years, and be fluid and in flux, with its backwards and forwards movement of feelings, expressed as longings and tensions, oftentimes remaining unresolved. This is evident in both of our stories, where we write about our experiences of immigration, interweaving our respective mother tongues with the English language.

Migrants brave the new world, going beyond the visible horizons, searching for what lies beyond: often it is both, excitement and challenge. Where the new horizon is not yet come into view, and the old one is vanishing in the distance, migrants often feel caught in the midst of transition, constantly wondering, where is 'home'? With this, there is also an intermingling of feelings of loss and longing. Helen longs for her friends in Hong Kong=, and Jasna reflects that, "loved ones tired of waiting for our return, leave this world."

Jasna's story denotes the temporal progression of acclimatization. She starts her poetic prose fully in Croatian, and as she progresses through the years of living in her new landscape, the two languages interweave, and the latter part of the poetic prose is written fully in English. Helen's story title, SteppingStones, itself denotes this movement between continents, the movement between Hong Kong and Canada. She too entwines the two languages, Cantonese and English, to describe her inward feelings and outward actions.

Because transition and self-identity are closely related, those of us experiencing this adaptation to change are advised to reconnect with our pre-existing ways of being in the world that define who we are (Boeijea et al., 2002; Bridges, 2004; Young et al., 2002). The transitional process encompasses "inner reorientation and self-redefinition" (Bridges, 2004, p.12), which requires us to redefine our sense of self and to re-develop our self-agency (Kwok, 2017). In other words, transition is not only a trajectory of making changes in life, but also a psychological process for tapping into one's current state of mind, feelings, and perspectives, while rediscovering and re-cultivating oneself (Selder, 1989). We depict this progression of transition as a "step by step" process, moving across the "stepping-stones" from one shore to the other. This process of transition cannot be rushed. It must be lived moment by moment over time within evolving relationships.

Selder (1989) and Bridges (2004) highlight that the essence of transition transpires when an individual's existing reality is disrupted, which leads to a forced or chosen adjustment that contributes to the construction of a new reality. And, in order to achieve the hoped-for future, it is during the process of transition that we make alterations, positive or negative. It involves one's ability to explore, confront, react to, reflect on, and rediscover the new possibilities and meaning for life (Kralik et al., 2006; Kwok, 2017).

In other words, to survive, immigrants face a steep learning curve in terms of acquiring a new language, new culture, and simple social norms, all of which further reinforce their identity as outsiders. Schwind uses the metaphor of a "transplanted outsider" whose roots, deeply connected to culture and family, are removed from their native soil and replanted into a strange new landscape (Lindsay et al., 2016, p. 585). The transplanted individual struggles to survive and strives to adapt to the new environment.

Studies reveal that one of the most profound experiences for immigrants is the feeling of being an outsider, which often influences the way they view themselves in relation to others, as well as their attachment to the new society (Amit, 2010; Ono, 2002; Verkuyten, 2008). Researchers have observed that the development of these feelings relies highly on social support, perception, and acceptance of immigrants' ethnic identity (Amit \& Bar-Lev, 2015; Lay \& Veerkuyten, 1999; Leung, 2001).

Jasna depicts the immigrants as the "fifthdimension people," who are hoping to cope with the impact of being transplanted into the new environment. This extra dimension is the story of our experiences prior to migration. It is like having an additional toe; it makes us the same, yet a little different. This extra appendage has been with us from birth and comes along whatever path we walk. No 
matter how long we are in the adoptive country, that "fifth-dimension" will always be part of who we are, our identity. What eventually makes the difference is whether we view this additional dimension as a burden or a gift. In a longitudinal study, Arredondo (1984) found that a sense of belonging is reflective of the extent to which individuals feel positively about themselves and how much they trust others. He suggests that initially immigrants may feel out of place, but will progressively develop a feeling of belonging, provided they are surrounded by a welcoming and accepting community. We add, however, that an immigrant's personal life philosophy also plays a significant role in how the transplanted individual adapts to the new landscape.

\section{Sense of Belonging}

Besten (2010) defines belonging as "a feeling of attachment and the meaning that people attribute to a particular place" (p. 182). Places are "spaces which people have made meaningful" (Cresswell, 2004, p. 7). In this context, Antonsich (2010) notes that to belong means situating ourselves in a space where we can feel personally and intimately connected, such as "home" (p.646). A home is fundamentally constructed to provide us with the feeling of security, protection, comfort, and to nourish our own values, culture, and self-identity without judgement. In other words, while immigrants are encouraged to establish recognition, membership, and participation in their new home, their need to develop a sense of connection and belonging is vital.

For immigrants, the feeling of belonging is associated with the need for acceptance and to be treated as meaningful beings within the new community. Research shows that immigrants' strong social connection to their family and community can mitigate social loneliness (Weiss, 1973). However, it is also argued that individuals can experience loneliness even when they are surrounded by a crowd, and conversely, be alone without feeling lonely (Madhavi et al., 2014). In fact, it is the quality of social relationships that makes immigrants feel validated and accepted as social beings and members of a community. In this way, their humanness is respected.

Feeling alone in a new land characterizes many immigrant experiences. Not having a sense of belonging is challenging for human beings, as it is foundational to the survival of our species.
Psychologists agree that having a sense of belonging is one of the basic needs for human beings (Baumeister \& Leary, 1995). In the case of immigrants, the process of settling in a new country involves more than accessing language training, education, housing, and employment (May, 2013; Yuval-Davis, 2006).

A sense of belonging is entwined closely with voice, of being able to communicate clearly, to be heard, seen, and included. In Jasna's story upon arrival to the new land, without being able to speak English, she describes her voice as uttering "muted words." In Helen's experience, her classmates assumed that she did not understand English because she did not immediately respond to their question, and excluded her from the group discussion. Helen writes in her story that her "voice screams silently," denoting a sense of constraint, and perhaps fear of ridicule, thus, leaving her feeling alone and excluded. Yet, it is the development of a sense of belonging that contributes to immigrants' integration and subjective well-being (Amit 2010, 2012; Capra \& Steindl-Rast, 1991; Massey \& Redstone, 2006; Phinney et al., 2001).

Language skills are part of our voice. It is through language that we express our thoughts, ideas and emotions, giving voice to our identity. In this way language skills help us articulate our place in the world. As a social species, this notion is very significant, as we seek communities where we can find a sense of belonging, where we feel understood and accepted. As immigrants, we are expected to put our cultural roots and identities aside to acculturate to the new social context. We are expected to learn a new language, norms, and culture, and establish experiences and skills, to adjust to our new home.

After immigration we are separated, not only from our country of origin, but also from our kin. Consequently, immigrants often experience feeling unsettled. When we returned home for a visit, after a prolonged separation, we both experienced culture shock in our respective countries of origin. We struggled speaking our respective mother tongues. We felt lost and frustrated.

For Helen, when she is in Toronto, she thinks of Hong Kong and its people. Yet, when she is in Hong Kong, she thinks of her Toronto home, but more as a physical place, than an emotional one. Returning to her place of birth, Helen recalls being embraced by 
her parents, feeling like she was coming into a safe harbour. So, when her father did not understand her Cantonese, it was jarring to her. She experienced once again a sense of displacement, worried that she let her parents down because she had changed. She did not want to disappoint them just because she had been transplanted to another landscape, fearing that the process may have damaged their bond.

Immigrants often return to their birth home, hoping to quench their thirst for belonging and inclusiveness. Wishing against all odds that the loved ones left behind would be the same comfortable arms they were prior to their departure, and that they could simply pick up where they had left off. Sadly, and realistically, this is not possible, especially the longer the time gap between departure and the returning visit. During the intervening time-space, both immigrants and their loved ones had changed. As Helen's story depicts, it is more than just the physical distance that needs to be bridged, it is the evolutionary chasm between the immigrants and those left behind that remains a challenge.

Hou and colleagues (2016) found that acculturation experience is highly associated with migrants' sense of belonging to both new and birth countries. They highlight the importance of immigrants maintaining a strong attachment to their cultural heritage, while at the same time engaging with the receiving society. Hou et al. believe that this balanced approach would strengthen immigrants' meaningful contribution to the new country.

As our respective roots grow into this new soil, we recognize that home is here now. It is something we both accept with a sense of resigned, yet appreciative acceptance. Being here in Canada for both of us, is being at home. Despite this, we recognize that we are of two worlds. We continue to be in the fluid tension between there and here. The longer we are in our new place, the deeper our roots grow, and the more at home we feel.

However, despite this acclimatization, from time to time, there is a feeling of being caught in limbo, or being torn. Helen observes, "However, my immigration experiences remain. The feelings of loneliness, fear, isolation, and insecurity are continuously intruding into my relationships with friends and family." Jasna seems to bring some resolution to this tension by the end of her poetic prose. She acknowledges that "we belong nowhere, and we belong everywhere." Reframing the tension into what we can be grateful for, allows a sense of expanded peace and contentment through resolution between loss and belonging.

The emotional part of ourselves is hardwired and forms part of who we are, our identity, and where we belong, our place in the world. This process requires time, social attention, and commitment to creating a person-centered approach that aims to explore individual's lived experiences of developing a sense of belonging, feeling "at home" in the new landscape (Black, 2002; George \& Selimos, 2019). Social attention refers to the creation of a supportive community, where we can try to find, and perhaps start to create, a sense of belonging. Although the tension abates over the years, it is often not fully resolved.

\section{IMPLICATION}

\section{Learning from Reflection}

As Dewey (1963) notes, "every experience should do something to prepare a person for later experiences of a deeper and more expansive quality" (p. 47), further underscoring that there is no learning without some reconstruction of our life events. By reflecting on our immigration experiences, the earlier internal uncertainty and insecurity became diminished. According to Meleis et al (2000), such critical reflection enhances the mastery of new skills and ways of living, as well as the development of a flexible sense of identity in the midst of change.

In both of our stories, we recognize that we left our respective birth countries for a better future. However, before such changes begin, Meleis and colleagues (2000) advise it is imperative to make sense of what is disordering our lives and challenging our relationships, routines, roles, perceptions, ideas, or identity. To do so, acknowledging and reflecting on lived experiences, caused by disruptive events, allows individuals to examine how their current situations are interrupted and discover ways to respond to living and being in the world (Lindsay et al., 2016).

Dewey observed that the "trouble with traditional education was not that it emphasized the external conditions that enter into the control of the experiences but that it paid so little attention to the 
internal factors which also decide what kind of experience is had" (p. 42). Chiu et al (2002) suggest that students with a higher sense of belonging may have fewer psychological issues and social problems, having greater possibility to show optimal cognitive and psychosocial functioning. Therefore, educators ought to explore what belonging means to the people in their educational care and examine how they can create a welcoming environment where mutual respect, empathy, and inclusion are demonstrated. Thus, educators play an important role in creating a supportive environment that fosters students' sense of social and emotional belonging, and wellbeing.

Educators need to recognize the acculturation differences of immigrant students and the negative effects on their learning and adaptation in the classroom. It is important to pay close attention to the communication dynamics between the students and their families, and examine the changes in their roles, attitudes, and behaviours, which may negatively affect their relationships and the acculturation experiences.

Being educators, who are immigrants, we recognize that the fundamental element of emotional belonging is based on mutual respect and trust. Our respective bodies of professional knowledge, practice, and identity as educators, have prepared us to be more sensitive and fully open to engaging with students from diverse backgrounds, by creating space for their storied biographies, their personal narrative, which are to be respectfully honoured.

Immigrant educators often indicate that they feel a strong connection with the students from any background, because they can easily articulate and share their concerns and desires for their learning. To ensure immigrant students are fully supported by the entire teaching team, not only immigrant educators, but the entire educational system should create a mentoring system for non-immigrant educators. Connecting immigrant and non-immigrant educators, to learn from and about each other, is integral to fostering a supportive community of student learners.

\section{CONCLUDING THOUGHTS}

By travelling through our personal (immigrant) and professional experiences temporally, from past to present, we discovered new concepts that reveal how the internal and external conditions shape our future ways of engagement. Examining our personal immigration experiences using Connelly and Clandinin's $(1990,2006)$ narrative inquiry self-study framework, which is informed by Dewey's three criteria of experience (continuity, relationship and situations), we came to appreciate the shared humanity in migration experiences. In our collaborative reflection, we highlight the human need for belonging, community, voice, and identity. Importantly, we recognize how our personal (inward) and social (outward) relationships and experiences inform who we are as persons and professionals, and how engaging in reflective dialogue, using creative self-expression, advances the quality of human life.

Engaging in reflective practice, aided by creative self-expression activities, we learn about ourselves and how our life events inform our present and future ways of being in the world, and especially for us as educators, in teaching-learning situations. By modeling engagement in reflective writing, we encourage our students to do the same. They are supported to puzzle through their own life events in order to better understand their current state of personal and professional being. Through this reflective process, they consider their future choices, which became apparent through reflection and dialogue. The reflective activity also supports students' engagement with the course curriculum, nurturing their curiosity for further learning.

As narrative inquirers we understand education to be a process of inquiry, where both educators and students bring their narrative histories, which "shape their encounters with each other, with us, and with course materials" (Schwind \& Lindsay, 2016, p. 482). In this way we acknowledge "the subjective, relational, contextual and constitutive nature of inquiry" (Butler-Kisber, 2010, p. 64). Using our stories, we demonstrate how our personal accounts contribute to building a "continuous life of experience, linking the past to the future from the standpoint of the present" (Bochner, 1997, p. 418). Having engaged in narrative inquiry self-study of our lived experiences, we have gained a deeper insight into how such significant life events as migration may have an impact on students with similar histories, and how we, as educators, can more effectively support them to engage in their academic work and their social relationships. 
Our hope is that educators from around the world will find our collaborative narrative inquiry self-study helpful as they engage in their own reflective process to consider how they, migrant or not, can best support their students to not only survive, but to thrive in their educational landscape.

\section{REFERENCES}

Aksenchuk, S. (2020). Personal illness experience of my adolescent self: A Narrative Inquiry self-study. Unpublished Masters Thesis. Ryerson University, Toronto, ON Canada.

Amit, K. (2010). Determinants of life satisfaction among immigrants from Western countries and from the FSU in Israel. Social Indicators Research, 96(3), 515-534.

Amit, K. (2012). Social integration and identity of immigrants from the FSU, Western countries and Ethiopia in Israel. Ethnic and Racial Studies, 35(7), 1287-1310.

Amit, K., \& Bar-Lev, S. (2015). Immigrants' sense of belonging to the host country: The role of life satisfaction, language proficiency, and religious motives. Social Indicators Research, 124(3), 947961.

Antonsich, M. (2010). Searching for belonging: An analytical framework. Geography

Compass, 4(6), 644-659.

Arredondo, P. M. (1984). Identity themes for immigrant young adults. Adolescence, 19(76), 977-93.

Baumeister, R. F., \& Leary, M. R. (1995). The need to belong: Desire for interpersonal attachments as a fundamental human motivation. Psychological Bulletin, 117(3), 497- 529.

Besten, D. O. (2010). Local belonging and 'geographies of emotions': Immigrant children's experience of their neighbourhoods in Paris and Berlin. Childhood, 17(2), 181-195. https://doi.org/10.1177/0907568210365649

Black, R. (2002). Conceptions of "home" and the political geography of refugee repatriation: Between assumption and contested reality in Bosnia-Herzegovina. Applied Geography, 22, 123138.

Bochner, A. P. (1997). It's about time: Narrative and the divided self. Qualitative Inquiry, 3(4), 418-438.

Boeijea, H., Duijnsteeb, M., Grypdonckb, M., \& Pool, A. (2002). Encountering the downward phase: biographical work in people with multiple sclerosis living at home. Social Science and Medicine, 55(6), 881-893.

Bridges, W. (2004). Transitions: Making Sense of Life's Changes. Da Capo Press.

Bullough, R. V., \& Pinnegar, S. (2001). Guidelines for quality in autobiographical forms of self-study research. Education Researcher, 30(3), 13-21.

Butler-Kisber, L. (2010). Qualitative inquiry: Thematic, narrative and arts-informed perspectives. Thousand Oaks.

Capra, E., \& Steindl-Rast, D. (1991). Belonging to the universe: Exploration on the frontiers of science and spirituality. Harper Collins.

Chiu, M. M., Pong, S., Mori, I., \& Chow, B. W. (2012). Immigrant students' emotional and cognitive engagement at school: A multilevel analysis of students in 41 countries. Journal of Youth and Adolescence, 41(11), 1409-1425. doi:10.1007/s10964-012-9763-x

Clandinin, D. J., \& Connelly, F. M. (1998). Personal experience methods. In N. K. Denzin, \& Y. S. Lincoln (Eds.), Collecting and interpreting qualitative materials (pp. 150-177). Sage Publications Inc.

Clandinin, D. J., \& Connelly, F. M. (2000). Narrative inquiry: Experience and story in qualitative research. Jossey-Bass Publishers.

Clandinin, D. J., \& Connelly, F. M. (2004). Knowledge, narrative, and self-study. In J. Loughran, M. L. Hamilton, V. LaBoskey, \& T. Russell (Eds.), International handbook of self-study of teaching and teacher education practices, (pp. 575-600). Kluwer Academic.

Connelly, F. M., \& Clandinin, D. J. (1988). Teachers as curriculum planners. Teachers College Press.

Connelly, F. M., \& Clandinin, D. J. (1990). Stories of experience and narrative inquiry. Educational Researcher, 19(5), 2-14. doi:10.3102/0013189X019005002

Connelly, F. M., \& Clandinin, D. J. (2006). Narrative inquiry. In J. L. Green, G. Camilli, \& P. B. Elmore (Eds.), Handbook of complementary methods in education research. (pp. 477-487). Lawrence Erlbaum Associates, Inc.

Cresswell, T. (2004) Place: A Short Introduction. Blackwell.

Dewey, J. (1916). Democracy and education: An introduction to the philosophy of education. Free Press.

Dewey, J. (1929). The quest for certainty: A study of the relation of knowledge and action. Minton, Balch \& Co. 
Dewey, J. (1963). Experience and education. Collier Books, Macmillan Publishing Company. (Originally published 1938)

Dinkelman, T. (2003). Self-study in teacher education: A means and ends tool for promoting reflective teaching. Journal of Teacher Education, 54(1), 618. doi:10.1177/0022487102238654

DiStasi, C. (2020). The reciprocal relationship of self and practitioner: A Narrative Inquiry self-study. Unpublished Masters Thesis. Ryerson University, Toronto, ON Canada.

Eisner, E. W. (2002). The arts and the creation of mind. Yale University Press.

George, G., \& Selimos, E. D. (2019). Searching for belonging and confronting exclusion: A personcentred approach to immigrant settlement experiences in Canada. Social Identities, 25(2), 125-140. https://doi.org/10.1080/13504630.2017.138183 4

Hou, F., Schellenberg, G., \& Berry, J. (2016). Patterns and determinants of immigrants' sense of belonging to Canada and their source country. Statistics Canada. http://www.statcan.gc.ca/pub/11f0019m/11f001 9m2016383-eng.htm

Hunt, D. E. (1987). Beginning with ourselves: In practice, theory, and human affairs. Brookline Books, OISE Press.

Kralik, D., Visentin, K., \& Van Loon, A. (2006). Transition: A literature review. Journal of Advanced Nursing, 55(3), 320-329. https://doi.org/10.1111/j.13652648.2006.03899.x

Kwok, O. L. H. (2017). Immigrant-early childhood educator's experience of working with immigrant children and their families: Arts-informed Narrative Inquiry self-study. Unpublished Masters Research Paper. Ryerson University, Toronto, ON Canada.

Lay, C., \& Verkuyten, M. (1999). Ethnic identity and its relation to personal self-esteem: a

comparison of Canadian-born and foreign-born Chinese adolescents. The Journal of Social Psychology, 139(3), 288_99.

Leung, C. (2001). The socio-cultural and psychological adaptation of Chinese migrant adolescents in Australia and Canada. International Journal of Psychology, 36(1), 8-19.

Lindsay, G. M. (2008). Who you are as a person is who you are as a nurse. In J.K. Schwind, \& G.M. Lindsay

(Eds.), From experience to relationships:
Reconstructing ourselves in education and healthcare. Information Age Publishing, Inc.

Lindsay, G., Schwind, J. K., Papaconstintanou, E. Smye, V., \& Cross, N. (2016). Autobiographical reflection on what it means to experience disruption. Reflective Practice, 17(5), 583-591. doi: 10.1080/14623943.2016.1184635

Madhavi, A. V. P., Guruge, S., Schwind, J., \& Schindel Martin, L. (2014). Exploring the experiences of loneliness among older Sinhalese immigrant women in Canada. Perspectives, 37(1), 6-14.

Massey, D. S., \& Redstone, A. I. (2006). Immigrant intentions and mobility in a global economy: The attitudes and behavior of recently arrived US immigrants. Social Science Quarterly, 87(5), 954971.

May, V. (2013). Connecting self to society: Belonging in a changing world. Palgrave MacMillan.

Meleis, A., Sawyer, L., Im E.-O., Hilfinger Messias, D., \& Schumacher, K. (2000). Experiencing transitions: An emerging middle-range theory. Advances in Nursing Science 23(1), 12-28.

Ono, H. (2002). Assimilation, ethnic competition, and ethnic identities of U.S.-born persons of Mexican origin. International Migration Review, 36(3), 726-745.

Phinney, J. S., Horenczyk, G., Liebkind, K., \& Vedder, P. (2001). Ethnic identity, immigration, and wellbeing: An interactional perspective. Journal of Social Issues, 57(3), 493-510.

Pinar, W. F. (1981). Life history and educational experience. Part two. Journal of Curriculum Theorizing, 3(1), 259-286.

Polanyi, M. (2009). The Tacit Dimension. Chicago: The University of Chicago Press. (Original work published 1966).

Schwind, J. K. (2003). Reflective process in the study of illness stories as experienced by three nurseteachers. Reflective Practice, 4(1), 19-32.

Schwind, J.K. (2008). Accessing humanness: From experience to research, from classroomto praxis. In J. K. Schwind \& G. M. Lindsay (Eds.), From experience to relationships: Reconstructing ourselves in education and healthcare (pp. 77-94). Charlotte, NC: Information Age Publishing Inc.

Schwind, J. K. (2016). Narrative Reflective Process: A creative experiential path to personal-knowing in teaching-learning scholarship. In J. Gingras, P. Robinson, J. Waddell, L. \& Cooper (Eds.), Teaching as scholarship: Preparing students for professional practice in community services. (pp. 137-154). Wilfrid Laurier University Press. 
Schwind, J. K., \& Lindsay, G. (2016). Arts-Informed Narrative Inquiry: Crossing boundaries of research and teaching-learning. LEARNing Landscapes, 9(2), p. 473-487.

Schwind, J. K., Cameron, D., Franks, J., Graham, C., \& Robinson, T. (2012). Engaging in narrative reflective process to fine tune Self as Instrumentof-Care. Reflective Practice, 13(2), 223-235. doi: 10.1080/14623943.2011.626030. 1-13, iFirst Article, 2011.

Selder, F. (1989). Life transition theory: the resolution of uncertainty. Nursing and Health Care 10(8), 437-451.

Shields, C., Novak, N., Marshall, B., \& Guiney Yallop, J. J. (2011). Providing visions of a different life: Selfstudy narrative inquiry as an instrument for seeing ourselves in previously unimagined places. Narrative Works, 1(1), 63-77.
Verkuyten, M. (2008). Life Satisfaction Among Ethnic Minorities: The Role of Discrimination and Group Identification. Social Indicators Research,89(3),391404.https://doi.org/10.1007/s11205-008-9239-2

Webster's Encyclopedic Unabridged Dictionary of the English Language. (1989). Portland House.

Weiss, R. S. (1973). Loneliness: The experience of emotional and social isolation. MIT Press.

Young, B., Dixon-Woods, M., Findlay, M., \& Heney, D. (2002). Parenting in a crisis: conceptualising mothers of children with cancer. Social Science and Medicine 55(10), 1835-1847.

Yuval-Davis, N. (2006). Belonging and the politics of belonging. Patterns of Prejudice, 40(3),197-214. doi:10.1080/00313220600769331 